\title{
Accuracy of methods used for susceptibility testing of Haemophilus influenzae in United Kingdom laboratories
}

\author{
J PHILPOTT-HOWARD, A SEYMOUR, JD WILLIAMS \\ From the Department of Medical Microbiology, The London Hospital Medical College, Turner Street, \\ London E1 $2 A D$
}

SUMMARY Antibiotic susceptibility test reports on 1841 strains of Haemophilus infuenzae from 25 microbiology laboratories were compared with results obtained with the same strains at The London Hospital Medical College. Of strains found to be sensitive to the antibiotics tested, $0.5 \%$ were reported as tetracycline-resistant, $1.6 \%$ as ampicillin-resistant, and $6.2 \%$ as trimethoprimresistant. Of strains found to be resistant to these antibiotics, $37 \%$ were reported as tetracyclinesensitive, $27 \%$ as ampicillin-sensitive, and $66.7 \%$ as trimethoprim-sensitive.

Factors found to be of significance in improving accuracy of sensitivity reporting included use of chromogenic cephalosporin and low-content antibiotic discs for detection of ampicillin resistance, and use of lysed blood agar rather than chocolated blood agar to detect trimethoprim sensitivity.

Determination of antibiotic resistance in Haemophilus inftuenzae has been shown to be significantly influenced by variations in bacterial inoculum size, ${ }^{1}$ growth media, ${ }^{2}$ and antibiotic content of senstivity test discs. ${ }^{3}$ New techniques such as detection of beta-lactamase production with chromogenic cephalosporin substrate ${ }^{4}$ have also become commonly used. Antibiotic sensitivity testing of $H$ infuenzae plays an important part in management of serious infections such as meningitis and septic arthritis, especially in view of increasing resistance of this organism to ampicillin and chloramphenicol. ${ }^{5-7}$

In a survey of antibiotic resistance in $H$ influenzae carried out in $1981,{ }^{5}$ clinical isolates of haemophili were sent from laboratories in the United Kingdom to The London Hospital Medical College (LHMC). In this paper antibiotic sensitivity test reports for these strains were analysed and compared with results obtained at LHMC; the accuracy of sensitivity testing at each laboratory could then be assessed. Analysis of methods used in laboratories enabled identification of those factors which are of most significance in testing antibiotics against $H$ influenzae.

\section{Material and methods}

Full details of sensitivity testing methodology at LHMC are contained in an appendix. Twenty-five clinical microbiology laboratories in the United Kingdom sent a total of 1841 isolates of $H$ infuen$z a e$ to LHMC during the three-month period February to April 1981. Each isolate was accompanied by a form with the sending laboratory's antibiotic sensitivity test results. Laboratories also provided details of their sensitivity test methods.

All strains were tested at LHMC using antibiotic discs containing either $10 \mu \mathrm{g}$ tetracycline, $2 \mu \mathrm{g}$ ampicillin, $1.25 \mu \mathrm{g}$ trimethoprim or $100 \mu \mathrm{g}$ sulphamethoxazole. Strains found to be resistant to tetracycline or ampicillin by the sending laboratory or by LHMC had minimum inhibitory concentrations (MICs) of tetracycline, ampicillin and trimethoprim determined by an agar dilution method, with an inoculum size of $10^{4}$ colony forming units (CFU); for sulphamethoxazole, a broth dilution method was used, the inoculum being $10^{4} \mathrm{CFU} / \mathrm{ml}$. In addition, ampicillin-resistant strains were tested with chromogenic cephalosporin to detect betalactamase production.

Antiobiotic resistance was defined as follows: for tetracycline, an MIC of $4 \mathrm{mg} / \mathrm{l}$ or greater indicated resistance; for ampicillin, all beta-lactamase- 
Table 1 Sensitivity test methods for Haemophilus infuenzae in 25 laboratories

\begin{tabular}{|c|c|c|c|c|}
\hline Laboratory & Sensitivity test agar & Growth factors added & $\begin{array}{l}\text { Incubation with } \\
\text { added } \mathrm{CO}_{2}\end{array}$ & Control organism \\
\hline $\begin{array}{l}\text { A } \\
B \\
C \\
D \\
E \\
F \\
G \\
H \\
I \\
J \\
K \\
L \\
M \\
N \\
O \\
P \\
Q \\
R \\
S \\
T \\
U \\
V \\
W \\
X \\
Y\end{array}$ & $\begin{array}{l}\text { Oxoid Isosensitest } \\
\text { Oxoid Isosensitest } \\
\text { Oxoid DST } \\
\text { TCS chocolate } \\
\text { Oxoid DST } \\
\text { Oxoid Isosensitest } \\
\text { Oxoid DST } \\
\text { Oxoid Sensitest } \\
\text { TCS chocolate } \\
\text { TCS chocolate } \\
\text { Oxoid DST } \\
\text { Mast SAF } \\
\text { Mast Mueller-Hinton } \\
\text { Oxoid DST } \\
\text { Lab M Agar No } 2 \\
\text { Oxoid Agar No } 2 \\
\text { Lab M Sensitivity test } \\
\text { Oxoid DST } \\
\text { Oxoid Columbia } \\
\text { Oxoid Isosensitest } \\
\text { Oxoid DST } \\
\text { Oxoid Agar No } 3 \\
\text { Oxoid Isosensitest } \\
\text { Oxoid DST }\end{array}$ & $\begin{array}{l}7 \% \text { LHB } \\
\text { Chocolated HB } \\
0.25 \% \text { LHB + NAD } \\
- \\
5 \% \text { LHB + NAD } \\
5 \% \text { LHB } \\
10 \% \text { chocolated HB } \\
5 \% \text { LHB } \\
- \\
\text { Chocolated HB } \\
\text { IsoVitalex } \\
-5 \% \text { LHB } \\
10 \% \text { HB + } 10 \% \text { serum } \\
10 \% \text { chocolated HB } \\
\text { Lysed blood cysteine+thiamine } \\
\text { Chocolated HB } \\
\text { Lysed HB } \\
\text { Chocolated HB } \\
\text { Chocolated HB } \\
\text { Chocolated HB } \\
5 \% \text { chocolated HB } \\
\text { Chocolated HB } \\
10 \% \text { LHB }\end{array}$ & $\begin{array}{l}- \\
+ \\
+ \\
+ \\
+ \\
+ \\
+ \\
+ \\
+ \\
+ \\
+ \\
+ \\
+ \\
+ \\
- \\
+ \\
+ \\
+ \\
+ \\
+ \\
+ \\
+ \\
+ \\
+\end{array}$ & $\begin{array}{l}-\overline{-} \\
\overline{-} \\
\text { Oxford Staph } \\
\text { Oxford Staph } \\
\text { H influenzae } \\
\text { Oxford Staph } \\
- \\
\overline{-} \\
\text { Oxford Staph } \\
\overline{-} \\
\text { Oxford Staph } \\
- \\
\text { - } \\
\overline{\text { Oxford Staph }} \\
\text { Oxford Staph } \\
\text { Oxford Staph } \\
\text { Oxford Staph } \\
\text { Oxford Staph } \\
\text { H influenzae } \\
\text { - } \\
\text { Oxford Staph }\end{array}$ \\
\hline
\end{tabular}

$\mathrm{HB}=$ horse blood

LHB = lysed horse blood

NAD $=$ Nicotinamide adenine dinucleotide

producing strains and beta-lactamase non-producers with MICs of $4 \mathrm{mg} / \mathrm{l}$ or more were considered to be resistant. Trimethoprim and sulphamethoxazoleresistant strains had MICs of greater than $4 \mathrm{mg} / \mathrm{l}$ and $16 \mathrm{mg} / \mathrm{l}$ respectively.

Participating laboratories were assigned code letters from A to Y. Although 1841 isolates of $H$ influenzae were received in the 1981 survey, certain antibiotic sensitivity tests were not performed or reported by the sending laboratories. Only those sensitivity test results reported for each strain are included in the figures.

\section{Results}

Table 1 summarises the disc sensitivity methods used by each laboratory, showing the type of agar, growth factors added, and incubation with or without added $\mathrm{CO}_{2}$, and control organism for comparing zone sizes. The methods for detection of betalactamase are included in Table 3.

Thirteen out of 25 laboratories used agar containing chocolated horse blood as a sensitivity test medium; the remainder used lysed horse blood $(0 \cdot 25-10 \%)$ with or without additional growth factors such as serum, nicotinamide adenine dinucleotide (NAD), cysteine and thiamine. One centre did not routinely perform antibiotic sensitivity testing other than using chromogenic cephalosporin to detect beta-lactamases. Four laboratories incubated sensitivity test plates in air without added carbon dioxide; their results were not significantly different from other centres.

Reporting of sensitivity results for each antibiotic was as follows:

\section{TETRACYCLINE}

Laboratory reports of 1565 tetracycline-resistant and sensitive strains are shown in Table 2 . Seven out of 1514 sensitive stains $(0.5 \%)$ were said to be resistant, the majority from one laboratory (U).

Of the 51 strains confirmed at LHMC to be resistant to tetracycline, $19(37 \cdot 3 \%)$ were reported to be sensitive by the sending laboratories. The centres using $10 \mu \mathrm{g}$ tetracycline discs did not detect 11 of 33 resistant strains (33\%); those centres using $25 \mu \mathrm{g}$ and $50 \mu \mathrm{g}$ discs missed 7 of 10 resistant strains $(70 \%)$. There is no significant difference in detection rates between these two groups. However, of the centres testing with $10 \mu \mathrm{g}$ discs, those using Oxoid Isosensitest agar detected 22 of 24 resistant strains $(91.7 \%)$ whereas laboratories using Oxoid DST agar detected significantly fewer resistant strains $\left(4\right.$ of $\left.9,(44.4 \%) ; \chi^{2}=6.13, p=<0.01\right)$.

Fifty-seven strains were of intermediate resistance, requiring tetracycline MICs of 1 or $2 \mathrm{mg} / \mathrm{l}$. Of these, $49(86 \%)$ were reported sensitive and 8 $(14 \%)$ as resistant. There is no correlation between disc size used and reporting of these strains.

\section{AMPICILLIN}

Of 1662 strains shown to be ampicillin-sensitive at 
Table 2 Reporting of tetracycline susceptibility in 24 laboratories

\begin{tabular}{|c|c|c|c|c|c|}
\hline Laboratory & $\begin{array}{l}\text { Disc used } \\
(\mu g)\end{array}$ & $\begin{array}{l}\text { No tetracycline- } \\
\text { sensituve strains }\end{array}$ & $\begin{array}{l}\text { No reported } \\
\text { resistant }\end{array}$ & $\begin{array}{l}\text { No tetracycline- } \\
\text { resistant strains }\end{array}$ & $\begin{array}{l}\text { No reported } \\
\text { sensitive }\end{array}$ \\
\hline $\begin{array}{l}\text { A } \\
\text { B } \\
\text { D } \\
\text { E } \\
\text { F } \\
\text { G } \\
\text { H } \\
\text { I } \\
\text { J } \\
\text { K } \\
\text { L } \\
\text { O } \\
\text { Q } \\
\text { R } \\
\text { T } \\
\text { U } \\
\text { W } \\
\text { W } \\
X \\
Y \\
\text { N } \\
\text { P } \\
\text { S } \\
\text { C } \\
\text { Total }\end{array}$ & $\begin{array}{l}10 \\
10 \\
10 \\
10 \\
10 \\
10 \\
10 \\
10 \\
10 \\
10 \\
10 \\
10 \\
10 \\
10 \\
10 \\
10 \\
10 \\
10 \\
10 \\
10 \\
25 \\
25 \\
25 \\
50\end{array}$ & $\begin{array}{r}193 \\
50 \\
46 \\
58 \\
36 \\
41 \\
73 \\
40 \\
6 \\
18 \\
87 \\
58 \\
106 \\
63 \\
33 \\
113 \\
34 \\
58 \\
48 \\
69 \\
39 \\
20 \\
173 \\
52 \\
1514\end{array}$ & $\begin{array}{l}1 \\
0 \\
0 \\
0 \\
0 \\
0 \\
0 \\
0 \\
0 \\
0 \\
0 \\
0 \\
0 \\
0 \\
0 \\
5 \\
0 \\
1 \\
0 \\
0 \\
0 \\
0 \\
0 \\
0 \\
7(0.5 \%)\end{array}$ & $\begin{array}{l}7 \\
1 \\
0 \\
1 \\
1 \\
2 \\
1 \\
2 \\
0 \\
1 \\
4 \\
0 \\
3 \\
3 \\
0 \\
6 \\
2 \\
0 \\
4 \\
3 \\
0 \\
0 \\
7 \\
3 \\
51\end{array}$ & $\begin{array}{c}0 \\
0 \\
1 \\
0 \\
2 \\
0 \\
2 \\
\frac{2}{0} \\
0 \\
1 \\
2 \\
1 \\
0 \\
1 \\
2 \\
- \\
5 \\
2 \\
19(37.3 \%)\end{array}$ \\
\hline
\end{tabular}

LHMC, $27(1.6 \%)$ were reported to be ampicillinresistant (Table 3). There was no correlation between the antibiotic content of discs used by the sending laboratories and the reporting of resistance in sensitive strains.

Of the strains found to be resistant to ampicillin at LHMC, 28 of 105 beta-lactamase producers (26.7\%) were reported as sensitive. Centres using chromogenic cephalosporin or other methods to detect beta-lactamase identified 57 of 74 betalactamase producers $(77 \%)$, whereas only 11 of 21 $(52 \%)$ were correctly identified by centres relying on disc sensitivity testing only $\left(\chi^{2}=6 \cdot 2, \mathrm{p}=\right.$ $<0 \cdot 01)$. Amongst laboratories not testing for betalactamase production, those using discs containing 2 $\mu \mathrm{g}$ and $5 \mu \mathrm{g}$ of ampicillin detected 11 of 13 beta-

Table 3 Ampicillin susceptibility testing in 25 laboratories

\begin{tabular}{|c|c|c|c|c|c|c|c|c|}
\hline \multirow[t]{2}{*}{ Laboratory } & \multirow{2}{*}{$\begin{array}{l}\text { Disc used } \\
(\mu g)\end{array}$} & \multirow{2}{*}{$\begin{array}{l}\text { Beta-lactamase } \\
\text { detection } \\
\text { method }^{*}\end{array}$} & \multicolumn{2}{|c|}{ Ampicillin-sensitive strains } & \multicolumn{4}{|c|}{ Ampicillin-resistant strains } \\
\hline & & & No sensitive & $\begin{array}{l}\text { No reported } \\
\text { resistant (\%) }\end{array}$ & $\begin{array}{l}\text { Beta-lactamase } \\
\text { producers }\end{array}$ & $\begin{array}{l}\text { No reported } \\
\text { sensitive }\end{array}$ & $\begin{array}{l}\text { Beta-lactamase } \\
\text { non-producers }\end{array}$ & $\begin{array}{l}\text { No reported } \\
\text { sensitive }\end{array}$ \\
\hline $\begin{array}{l}\text { D } \\
\text { E } \\
\text { F } \\
\text { H } \\
\text { J } \\
\text { L } \\
\text { T } \\
\text { V } \\
\text { X } \\
\text { A } \\
\text { K } \\
\text { B } \\
\text { G } \\
\text { N } \\
\text { O } \\
\text { P } \\
\text { R } \\
\text { U } \\
\text { W } \\
\text { Y } \\
\text { C } \\
\text { I } \\
\text { Q } \\
\text { S } \\
\text { M } \\
\text { Tatal }\end{array}$ & $\begin{array}{l}2 \\
2 \\
2,10 \\
2 \\
2 \\
2 \\
2 \\
2,10 \\
2 \\
5 \\
5 \\
10 \\
10 \\
10 \\
10 \\
10 \\
10 \\
10 \\
10 \\
10 \\
25 \\
25 \\
25 \\
25 \\
-\end{array}$ & $\begin{array}{l}\frac{1}{2} \\
\frac{1}{1} \\
\frac{1}{1} \\
\frac{3}{3} \\
\frac{1}{2} \\
\frac{1}{2,4} \\
\frac{1}{1} \\
\frac{1}{1} \\
\frac{1}{1}\end{array}$ & $\begin{array}{r}42 \\
57 \\
39 \\
67 \\
5 \\
83 \\
31 \\
33 \\
47 \\
188 \\
18 \\
46 \\
39 \\
37 \\
56 \\
20 \\
62 \\
113 \\
81 \\
60 \\
53 \\
42 \\
108 \\
165 \\
170 \\
1662\end{array}$ & $\begin{array}{ll}1 & (2 \cdot 4) \\
1 & 1 \cdot 7 \\
1 & 2 \cdot 6) \\
1 & (1 \cdot 5) \\
0 & \\
0 & \\
4 & (12 \cdot 9) \\
0 & \\
0 & \\
3 & (1 \cdot 6) \\
3 & (16 \cdot 6) \\
1 & (2 \cdot 1) \\
0 & \\
6 & (16 \cdot 2) \\
0 & \\
0 & \\
1 & (1 \cdot 6) \\
0 & \\
0 & \\
0 & \\
2 & (3 \cdot 8) \\
3 & (7 \cdot 1) \\
0 & \\
0 & \\
0 & \\
27 & (1 \cdot 6 \%)\end{array}$ & $\begin{array}{r}4 \\
4 \\
2 \\
6 \\
1 \\
8 \\
1 \\
3 \\
4 \\
8 \\
1 \\
5 \\
5 \\
1 \\
2 \\
0 \\
3 \\
9 \\
5 \\
2 \\
2 \\
4 \\
1 \\
13 \\
11 \\
105\end{array}$ & $\begin{array}{l}0 \\
2 \\
0 \\
1 \\
1 \\
1 \\
1 \\
1 \\
0 \\
1 \\
0 \\
1 \\
4 \\
0 \\
0 \\
1 \\
0 \\
3 \\
2 \\
0 \\
2 \\
1 \\
4 \\
2 \\
28(26 \cdot 7 \%)\end{array}$ & $\begin{array}{l}0 \\
0 \\
0 \\
1 \\
0 \\
0 \\
0 \\
0 \\
1 \\
2 \\
0 \\
1 \\
0 \\
0 \\
0 \\
0 \\
1 \\
0 \\
0 \\
0 \\
0 \\
0 \\
0 \\
2 \\
1 \\
9\end{array}$ & 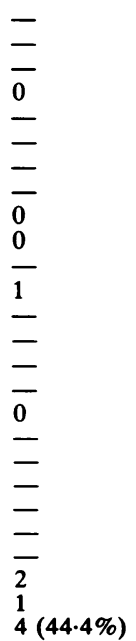 \\
\hline
\end{tabular}

*Beta-lactamase detection methods: 1: chromogenic cephalosporin; 2: Mast Betatest; 3: Clover leaf; 4: Acidometric. 
lactamase producers $(84.6 \%)$; this compares with detection of 4 of 11 beta-lactamase producers (36.4\%) by laboratories using $10 \mu \mathrm{g}$ and $25 \mu \mathrm{g}$ ampicillin discs $\left(\chi^{2}=4.03, \mathrm{p}=<0.05\right)$.

Of nine ampicillin-resistant beta-lactamase nonproducers, four were reported as sensitive $(44 \%)$. Laboratories which did not detect these strains either relied on the chromogenic cephalosporin test alone (with no disc test) or used ampicillin discs containing $10 \mu \mathrm{g}$ or $25 \mu \mathrm{g}$ ampicillin. Laboratories that detected these strains used discs containing 2,5 or $10 \mu \mathrm{g}$ ampicillin.

Fifty-nine strains were of intermediate resistance-that is, beta-lactamase non-producers with ampicillin MICs of 1 or $2 \mathrm{mg} / \mathrm{l}$. Forty-three of these $(73 \%)$ were reported as sensitive, and 16 $(27 \%)$ as resistant. Centres using low content discs ( 2 and $5 \mu \mathrm{g}$ ) reported significantly more as resistant, compared with centres using high content ampicillin $\operatorname{discs}\left(\chi^{2}=4 \cdot 82, p=<0 \cdot 05\right)$.

\section{TRIMETHOPRIM}

Only results from laboratories reporting individual trimethoprim sensitivities are shown in Table 4; those using cotrimoxazole discs are not included.

Fifty-two of 838 trimethoprim-sensitive strains were reported as resistant $(6 \cdot 2 \%)$. One centre (D) accounted for 16 of these strains. Those centres using chocolated blood agar as a sensitivity test medium reported significantly more sensitive strains as resistant (30 of $359,8.4 \%$ ) compared with centres using lysed blood or other additives (22 of $\left.479,4.6 \% ; \chi^{2}=4.99, p=<0.05\right)$.

Of 15 strains found at LHMC to be trimethoprim-resistant, $10(66.7 \%)$ were reported as sensitive; there was no correlation between the accuracy of reporting and the laboratory methods used.

\section{SULPHONAMIDE}

The sulphamethoxazole disc and MIC testing at LHMC did not correlate sufficiently closely (correlation coefficient $r=-0.55$ ) for assessment of laboratory performance to be made.

\section{CHLORAMPHENICOL}

Although reporting of this antibiotic was not specifically requested, no centres indicated chloramphenicol resistance for any of the 19 strains with MICs of $4 \mathrm{mg} / \mathrm{l}$ or more.

\section{Discussion}

Analysis of laboratory performance in antibiotic sensitivity testing can help to identify the commonest causes of error and improve the accuracy of the sensitivity test, upon which the clinician may depend for choice of antibiotic therapy.

In this study, participating laboratories were noted to use widely differing sensitivity test methods for Haemophilus infuenzae (Table 1). However, only a few factors were found to be of significance in terms of identifying resistant strains. There were few false reports of tetracycline resistance $(0.5 \%)$; in contrast, $37 \%$ of the tetracycline-resistance strains were reported as sensitive. The reasons for this are not clear, but variations in concentrations of divalent cations are known to influence the tetracycline sensitivity test ${ }^{8}$ and a significant difference in accu- $?$ racy of reporting of resistance was found between centres using Oxoid Isosensitest agar and those using Oxoid DST agar. Disc testing of a further 100 tetracycline-sensitive and resistant strains using both of these media could not confirm that there was any significant difference between them in zone sizes around 10,25 and $50 \mu \mathrm{g}$ discs.

Detection of ampicillin-resistant strains was

Table 4 Reporting of trimethoprim susceptibility in 14 laboratories

\begin{tabular}{|c|c|c|c|c|c|}
\hline Laboratory & $\begin{array}{l}\text { Disc used } \\
(\mu g)\end{array}$ & $\begin{array}{l}\text { No trimethoprim- } \\
\text { sensitive strains }\end{array}$ & $\begin{array}{l}\text { No reported } \\
\text { resistant }\end{array}$ & $\begin{array}{l}\text { No trimethoprim- } \\
\text { resistant strains }\end{array}$ & $\begin{array}{l}\text { No reported } \\
\text { sensitive }\end{array}$ \\
\hline $\begin{array}{l}\text { E } \\
\mathbf{F} \\
\mathbf{G} \\
\mathbf{H} \\
\mathbf{R} \\
\mathbf{S} \\
\mathbf{U} \\
\mathbf{V} \\
\mathbf{A} \\
\mathbf{D} \\
\mathbf{N} \\
\mathbf{P} \\
\mathbf{X} \\
\mathbf{Y} \\
\text { Total }\end{array}$ & $\begin{array}{l}1.25 \\
1.25 \\
1.25 \\
1.25 \\
1.25 \\
1.25 \\
1.25 \\
1.25 \\
2.5 \\
2.5 \\
2.5 \\
2.5 \\
2.5 \\
2.5\end{array}$ & $\begin{array}{r}60 \\
35 \\
44 \\
74 \\
52 \\
12 \\
121 \\
36 \\
197 \\
37 \\
39 \\
18 \\
51 \\
62 \\
838\end{array}$ & $\begin{array}{r}3 \\
1 \\
0 \\
1 \\
1 \\
0 \\
4 \\
3 \\
5 \\
16 \\
4 \\
3 \\
3 \\
8 \\
52(6 \cdot 2 \%)\end{array}$ & $\begin{array}{l}0 \\
0 \\
1 \\
0 \\
4 \\
1 \\
1 \\
0 \\
1 \\
2 \\
0 \\
0 \\
1 \\
4 \\
15\end{array}$ & $\begin{array}{l}- \\
0 \\
-3 \\
1 \\
\frac{1}{0} \\
\frac{2}{-} \\
\frac{1}{2} \\
10(66.7 \%)\end{array}$ \\
\hline
\end{tabular}


shown to be significantly improved with the use of low content ampicillin discs containing 2 or $5 \mu \mathrm{g}$ of antibiotic, and with the use of beta-lactamase detection methods such as chromogenic cephalosporin. On theoretical grounds, laboratories using betalactamase-detecting methods alone will not detect ampicillin-resistant beta-lactamase non-producers; a disc sensitivity test is required. In view of the increasing cost of chromogenic cephalosporin, laboratories may prefer to use a low content ampicillin disc test and reserve beta-lactamase detection methods for those haemophili with a diminished zone of inhibition.

Strains of $H$ inftuenzae showing a low level of resistance to ampicillin and tetracycline were frequently reported as sensitive to the antibiotic. Whether or not infections due to these strains will respond to normal doses of antibiotic is not known.

The results of trimethoprim and sulphonamide sensitivity testing were the least satisfactory. Sensitivity tests with these antibiotics present difficulties with many organisms, including haemophili; antibiotic antagonists are present in certain bloodcontaining media, and the edges of the inhibition zones around these antibiotics are more frequently indistinct. For example, 10 of the 15 trimethoprimresistant strains were reported as sensitive. Trimethoprim-sensitive strains were more commonly reported to be resistant by those laboratories using chocolate horse blood agar rather than lysed blood agar; this may be because trimethoprim antagonists are only inactivated by lysis of red cells. A satisfactory method for sulphonamide testing of $H$ influenzae has not been described and for this reason we have not included the results in this report.

Sensitivity test methods used by a laboratory should provide accurate and reproducible results yet not require techniques impractical for routine use. The most important requirement is that antibiotic resistance is not missed, as ineffective chemotherapy may be commenced, and result in increased morbidity and mortality. The detection of strains resistant to ampicillin, tetracycline, trimethoprim or chloramphenicol is of particular importance.

\section{Appendix}

\section{SENSITIVITY TEST METHODS AT LHMC \\ Strains}

Isolates of $\boldsymbol{H}$ infuenzae were sent to LHMC from 25 clinical microbiology laboratories in the United Kingdom during a three month period in 1981 . Identity of these strains was confirmed using routine bacteriological techniques.
Disc sensitivity testing

Pure cultures of each strain were inoculated into nutrient broth (Oxoid) supplemented with 5\% Fildes' extract (Difco). After incubation at $37^{\circ} \mathrm{C}$ for $5 \mathrm{~h}, 1 / 100$ dilution in peptone water was prepared and used to seed the surface of Diagnostic Sensitivity Test agar (Oxoid) supplemented with $0.25 \%$ lysed horse blood and $10 \mathrm{mg} / \mathrm{l}$ nicotinamide adenine dinucleotide (BDH Chemicals Ltd.). Filter paper discs, $6 \mathrm{~mm}$ in diameter and containing $10 \mu \mathrm{g}$ tetracycline, $2 \mu \mathrm{g}$ ampicillin, $10 \mu \mathrm{g}$ chloramphenicol, $1.25 \mu \mathrm{g}$ trimethroprim or $100 \mu \mathrm{g}$ sulphamethoxazole, were applied to the surface. The plate was incubated in an atmosphere of $95 \%$ air and $5 \% \mathrm{CO}_{2}$ at $37^{\circ} \mathrm{C}$ for $18 \mathrm{~h}$.

Determination of minimum inhibitory concentration The minimum inhibitory concentrations (MICs) of the five antibiotics used for disc testing were measured for those strains showing a reduced zone diameter (less than $20 \mathrm{~mm}$ ) to one or more of the antibiotics tested. In addition MICs were measured for any strain reported by the sending laboratory to be resistant to tetracycline or ampicillin, regardless of the result of disc testing at LHMC. An agar dilution method was used for determining MICs of all antibiotics except sulphamethoxazole. Doubling dilutions of each antibiotic were prepared in Diagnostic Sensitivity Test agar (Oxoid), supplemented with $0.25 \%$ lysed horse blood and $10 \mathrm{mg} / \mathrm{l}$ nicotinamide adenine dinucleotide; final antibiotic concentrations ranged from 0.015 to $128 \mathrm{mg} / \mathrm{l}$. With a Denley multipoint inoculator $0.003 \mathrm{ml}$ of a $1 / 100$ dilution of a $5 \mathrm{~h}$ broth culture was applied to the surface of the agar. The number of organisms in the inoculum was approximately $10^{4}$. The plates were incubated in an atmosphere of $95 \%$ air and $5 \% \mathrm{CO}_{2}$ for $18 \mathrm{~h}$.

Minimum inhibitory concentrations of sulphamethoxazole were determined by a broth dilution method using Iso-Sensitest broth (Oxoid) supplemented with $0.25 \%$ lysed horse blood and 10 $\mathrm{mg} / \mathrm{l}$ nicotinamide adenine dinucleotide. In contrast to agar dilution methods, this produced end points that could be read without difficulty using an inoculum of $10^{4} \mathrm{CFU} / \mathrm{ml}$.

The regression lines for each of the antibiotics used are shown in the Figure. The recommended zone diameters for discrimination of sensitive and resistant strains using the above sensitivity test methods are: ampicillin, $2 \mu \mathrm{g}$ disc: $20 \mathrm{~mm}$; tetracycline, $10 \mu \mathrm{g}$ disc: $20 \mathrm{~mm}$; trimethoprim, 1.25 $\mu \mathrm{g}$ disc: $25 \mathrm{~mm}$; chloramphenicol, $10 \mu \mathrm{g}$ disc: $20 \mathrm{~mm}$. 

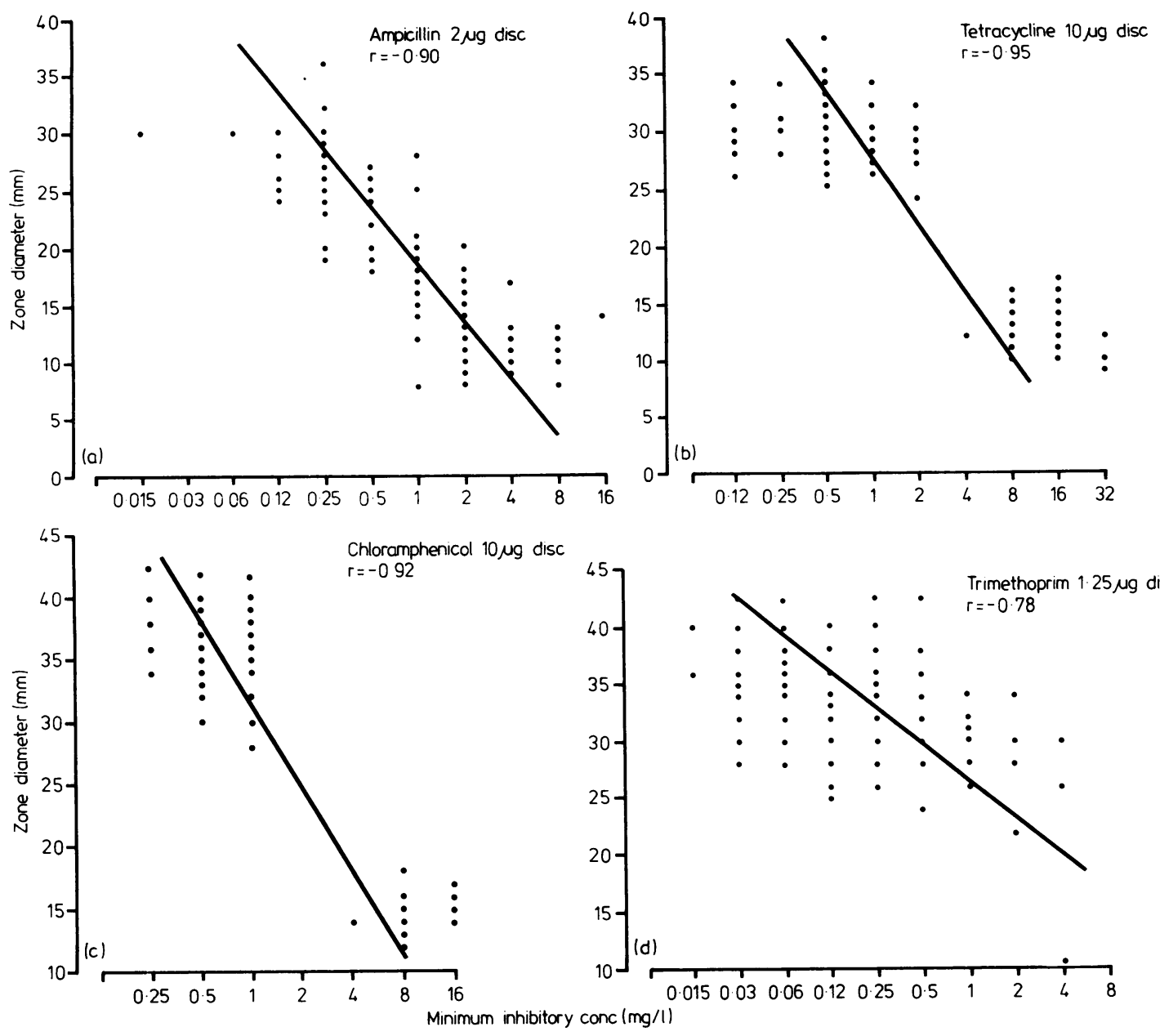

Regression lines for $H$ infuenzae.

\section{References}

' Howard AJ, Hince CJ. Ampicillin resistance in Haemophilus infuenzae (Letter), Lancet 1980; 1359.

${ }^{2}$ Garrod LP, Waterworth PM. A study of antibiotic sensitivity testing with proposals for simple uniform methods. J Clin Pathol 1980;24:779-89.

${ }^{3}$ Williams JD, Kattan S. Haemophilus species. In: Reeves DS, Phillips I, Williams JD, Wise R, eds. Laboratory methods in antimicrobial chemotherapy. Edinburgh: ChurchillLivingstone, 1978.

4 O'Callaghan CH, Morris A, Kirby SM. Novel method for the detection of beta-lactamases using a chromogenic cephalosporin substrate. Antimicrob Agents Chemother 1972;i:283-8.

${ }^{5}$ Philpott-Howard J, Williams JD. Increase in antibiotic resistance in Haemophilus infuenzae in the United Kingdom since 1977: Report of a study group. Br Med J 1982;284:1597-1601.
- Ward JT, Tsai TF, Filice GA, Drasar DW. Prevalence of ampicillin- and chloramphenicol-resistant strains of Haemophilus infuenzae causing meningitis and bacteraemia: national survey of hospital laboratories. $J$ Infect Dis 1978;138:421-4.

7 Jokipii L, Jokipii AMM. Emergence and prevalence of betalactamase-producing Haemophilus infuenzae in Finland and susceptibility of 102 respiratory isolates to eight antibiotics. $J$ Antimicrob Chemother 1980;6:623-31.

${ }^{8}$ Price KE, Zolli Z, Atkinson JG, Luther HG. Antibiotic inhibitors. II. Studies on the inhibitory action of selected divalent cations for oxytetracycline. Antibiot Chemother 1957;7:689-701.

Requests for reprints to: Dr J Philpott-Howard, Department of Medical Microbiology, The London Hospital Medical College, Turner Street, London E1 2AD, England. 